\title{
Reconfiguración espacial y modelos de apropiación y uso del territorio en la Patagonia chilena: migración por cambio de estilo de vida, parques de conservación y economía de la experiencia ${ }^{1}$
}

\author{
Juan Carlos Rodríguez Torrent ${ }^{2}$, Sonia Reyes Herrera ${ }^{3}$ y Fernando \\ Mandujano Bustamante ${ }^{4}$
}

\begin{abstract}
RESUMEN
Comprender las transformaciones que experimentan los territorios en la sociedad global, implica situarlos en el proceso de redefinición capital-naturaleza en el marco del capitalismo extractivista. ¿Qué lugar ocupa la Patagonia chilena a partir del valor otorgado a la naturaleza? Se postula que la singularidad que ofrece el espacio y paisaje patagónicos posibilita el desarrollo de distintas conceptualizaciones como producciones de significado material y simbólico, identificando tres cambios fundamentales que representan distintos modelos de apropiación, uso y reconfiguración del territorio que se sustentan sobre la conceptualización de la naturaleza como un commodity: 1) Migración por cambio de estilo de vida, 2) Parques de conservación mediante la venta de bonos de carbono y filosofía biocéntrica y 3) Economía de la experiencia y turismo. Los resultados corresponden a una investigación con enfoque cualitativo y sincrónico, basada en una estrategia de triangulación de datos provenientes de diferentes fuentes primaras y secundarias.
\end{abstract}

Palabras clave: Modelos de apropiación, naturaleza, capitalismo, Patagonia.

\begin{abstract}
Understanding territorial transformations in the framework of a global society implies approaching them from the perspective of redefining the capital-nature relationship, as outlined by extractive capitalism. What place does Chilean Patagonia holds in reference to the value assigned to nature? It is posited here that the singularity offered by the patagonic territory and landscape allows for the development
\end{abstract}

\footnotetext{
Este trabajo es parte del proyecto Fondecyt 1120795 "Etnografía de la colonización y recolonización de Chiloé Continental. Actores, intercambios y conflictos". Artículo recibido el 10 de marzo de 2015, aceptado el 3 de octubre de 2015 y corregido el 11 de noviembre de 2015.

2 Facultad de Arquitectura, Universidad de Valparaíso (Chile). E-mail: juancarlosrodriguezt@yahoo.com
}

Instituto de Sociología, Universidad de Valparaíso (Chile). E-mail: sonia.reyes@uv.cl

4 Facultad de Ciencias de la Educación, Universidad de Playa Ancha (Chile). E-mail: fmandujan@yahoo.es 


\begin{abstract}
of new conceptualizations in order to generate material and symbolic meaning. Therefore, it is possible to identify three fundamental changes that represent different modes of territorial appropriation, land use and configuration models, supported by the conceptualization of nature as a commodity: 1) Migration in search a change in lifestyle; 2) national parks defined through the sale of carbon credits and a biocentric philosophy and 3) Tourism and the experience-based economy. Our results correspond to a qualitative and synchronic research based approach, using a three-way systemic analysis of data gathered from various primary and secondary sources.
\end{abstract}

Key words: Regional zoning models, Nature, Capitalism, Patagonia.

Existe una amplia bibliografía sobre los cambios operados en la estructura del capitalismo en su fase posindustrial y de mayor consenso sobre sus efectos en los ecosistemas, habiendo "un acuerdo común en el que el control de la naturaleza tiende a ser definitivo o irreversible" (Nouzeilles, 2002:11). En general, se reconoce que los límites posibles de explotación o la biocapacidad del planeta han sido sobrepasados y que estamos en una condición de riesgo extremo debido a que la acción antrópica no se detiene y afecta todos los ecosistemas. Además de un importante declive de las ciudades industriales y un aumento de la velocidad con la que circulan las personas y los objetos. Paralelamente, a la instalación de la transitoriedad y la gran dinámica de flujos como elemento central en el modelo dominante, se suman elementos subjetivos como el sentimiento de falta de vínculos y arraigo, de trascendencia histórica y estabilidad, lo que ha desencadenado un descontento y un cierto hastío sobre los beneficios de la modernidad y una redirección de la mirada hacia aquellos lugares que puedan ofrecer esperanza y un nuevo horizonte de vida. Con ello, de manera íntima se abre la posibilidad de representar las relaciones con el hábitat de una nueva forma; poniendo límites y, así expandir la propia conciencia, pero también de consumirlo a través de distintas alternativas que son producto del marketing, los negocios, el desarrollo de la ciencia y formas simuladas y/o simbólicas propias de la reestructuración capitalista (Harvey, 1989; Brohman, 1996; Stonich, 1998).

De este modo, es difícil pensar en la naturaleza desde una conciencia verde o desde una ideología "clorofila", en términos de Mario Gaviria (Rodríguez y Requena, 2014: 170), si no observamos las transformaciones del capitalismo en las últimas tres décadas y, específicamente, en su "regeneración", "reorganización" o su forma "floreciente" como "modelo de gestión" en términos de Boltanski y Chiapello (2002). Esto es, una estrategia para "obtener beneficios puramente especulativos mediante los cuales se incrementa el capital sin que sea necesaria la inversión en actividades productivas" (2002: 20), como ocurre con los procesos de commodification de la naturaleza en lugares seleccionados y ubicados en antiguas periferias de la industrialización como la Patagonia, que implica un proceso de acumulación de capital y creación de valor material y simbólico mediante la transformación a nivel local, a través de prácticas e itinerarios, del valor de uso en valor de cambio como ocurre con el turismo ${ }^{5}$. Es en esta periferia (que podemos Ilamar del placer para muchos y anónimo para algunos de los afuerinos) donde hoy se constituye un área de negocios mediante una mercantilización del paisaje natural y social que la convierte en centro, con una densidad demográfica inferior a un habitante por kilómetro, concentrada principalmente en las ciudades de Punta Arenas (Magallanes) y Coyhaique (Aysén), y distribuida en pequeños poblados. Esto hace que dentro de sus $265.276 \mathrm{~km}^{2}$ exista una gran extensión territorial al margen de la integración nacional, con mucha autonomía cultural y social, sin políticas de colonización efectivas o dirigidas a la creación de asentamientos, pero también propicia para el descubrimiento externo.

Mediados por el mercado, los canales de TV por cable han desarrollado una impresio-

\footnotetext{
5 Nos referimos, por ejemplo, a cómo el caballo, animal indispensable para las labores de una economía ovejera en la Patagonia, se convierte en indispensable dentro de la experiencia de inmersión en la vida local. Asimismo, viejas estancias convertidas en hoteles boutique. También, cómo las rutas secundarias que parecen no conducir a ninguna parte, se convierten en lugar de exploración para ciclistas aventureros.
} 
nante promoción y merchandising de lugares que hay que visitar y ecosistemas que se deben proteger, estimulando la sensibilidad, el deseo y la imaginación conforme a la elaboración de un nuevo mapa mental y económico dentro del actual capitalismo. Lo mismo encontramos en las revistas de viajes de los periódicos dominicales. Algunos países, apoyados por su rica biodiversidad, han fortalecido y promocionado su imagen en el exterior a partir del fomento de macro y microespacios que se deben conocer. Las estanterías de los bookstore de los aeropuertos tienen un amplio abanico de libros y revistas, con impresionantes fotografías de destinos únicos e inolvidables, aquellos imposibles de no vivir y apreciar antes de morir. Lo mismo se ha propuesto en las revistas de las compañías aéreas. Hay un despliegue de un aparato retórico de producción de sentidos y encuadre de imágenes que conducen al voyeurismo y consumo de lo natural y cultural "autóctono" en un contexto de mercantilización neoliberal, ligado a la belleza y nostalgia de aquello que escapa a la vulgarización de la ciudad y del turismo masivo. En este sentido, estamos bombardeados por una iconografía de la seducción y del placer que alcanza un alto despliegue en distintos formatos y soportes, como parte de una nueva economía y área de negocios que implica entre los efectos significativos, otorgar nuevas valorizaciones a la tierra a través de la jerarquización y construcción de geomarcas y geosímbolos (Rodríguez et al., 2014; Medina et al., 2013) que tienen como efectos desplazar o redefinir los ejes económicos de la población local y desarroIlar proyectos inmobiliarios y turísticos, como está ocurriendo con la Patagonia en Chile y Argentina.

En ese escenario, la Patagonia es destacada como objeto-contemplación y por la imagen del "fin del mundo", la que corresponde a la Marca Registrada de la Secretaría de Turismo de Tierra del Fuego Argentina (Giucci, 2014: 2014), así como en Chile, Porvenir extiende el límite para afirmar que está "más allá del fin del mundo". Con matices, en las tierras australes se exaltan por una parte, geosímbolos como el río, el glaciar, los bosques vírgenes, cóndores, las familias de guanacos y huemules, y por otra, como signo de detención del tiempo, es reflejo de un gaucho en que se resalta su piel curtida y llena de surcos por el clima austral, con una larga manta y su boina, en su cabalgadura y acom- pañado por cientos de ovejas y los perros; en otras, en un fogón, consumiendo mate. También, es infaltable un pescador deportivo en un río de flujo libre o un ciclista solitario que tendrá mil historias para contar a su retorno, el que venderá fotografías a algún magazine. No es extraño encontrar invitaciones a conocer, en formatos trilingües, la "bodega del fin del mundo", los viñedos de la Patagonia donde se elaboran "vinos reconocidos y diferenciados de todo el mundo", "ruta Patagonia salvaje", participar en torneos de "comida y coctelería fusión", en la "Patagonia International Marathon", practicar "trekking at the end of the world", o bajar el río Futaleufú y el Palena en kayak ${ }^{6}$.

Una parte de las ciencias sociales y humanas han estudiado desde diferentes perspectivas teóricas y metodológicas estas cuestiones y estamos instalados en una transversal discusión sobre los impactos ambientales de las actividades productivas agrícolas, mineras e industriales y las ambigüedades discursivas y producciones de sentido de la sustentabilidad y la sostenibilidad en el formato de acumulación del capitalismo global (Aliste y Urquiza, 2010) y, procesos de neocolonización (Núñez et al., 2014). Esto es, sobre la nueva relación entre sociedad-naturaleza, lo que constituye la emergencia de una popularidad nunca antes vista y un reclamo para pensar modelos y nuevos regímenes de acción social, de las formas de producción de bienes industriales y agrícolas, y de la propia noción de bienestar. De igual manera, como cuestión general y aplicable a la Patagonia chilena, encontramos dos grandes ejes reflexivos siguiendo a Candido et al. (2014): a) las posibilidades del mundo en general; b) las posibilidades de la propia vida.

Así, como conciencia de las malas prácticas, el factor natural y medioambiental ha sufrido un exponencial crecimiento después de la Cumbre de la Tierra, en Río 2012, reemplazando viejas banderas de lucha clásicas del siglo XX. Y, conforme a ello, podemos decir que debido a las externalidades de nuestra forma de vida, la naturaleza, como nunca, entra al juego institucional de la democracia,

\footnotetext{
6 También resulta relevante para estos propósitos el que no existan enfermedades, animales peligrosos y violencia.
} 
convirtiéndose en un eje inexcusable de referencia de los Estados y partidos políticos. Asimismo, reconocemos un importante lobby ecologista con presencia mediática y, lo más importante, estamos frente a localidades que alcanzan visibilidad a través de la ocupación de las redes sociales para denunciar amenazas y una opinión pública alerta y sensibilizada frente a todo conflicto ambiental. Con ello, se ha producido una importante patrimonialización de la naturaleza y, extensivamente, de algunos modos de vida, la refiguración y valoración jerarquizada de lugares únicos o place commodification en términos de Britton (1991); hasta hace poco inaccesibles, con flora y fauna endémica, como ocurre con la Patagonia chilena y argentina, instalándose ampliamente la necesidad de mejorar la gobernanza ambiental, fortalecer los medios de vida sustentables de una comunidad, evaluar la capacidad de carga de ecosistemas y poblados, y conservar la biodiversidad.

Esta condición que avanza al menos hacia la contemplación, no oculta que la prevalencia de la racionalidad capitalista también convierte a la naturaleza en mercancía y que, extensivamente, se produzca un proceso de subordinación paralelo de la sociedad a condiciones de rentabilidad y beneficio, creándose un nuevo mercado de consumo de lugares prístinos destinados al descanso, al autocontrol de experiencia del tiempo y la aventura. En este esquema, es difícil sostener la posibilidad de agregar valor al territorio si no existe el potencial paisajístico y dotación de una rica biodiversidad, ya que estos ejes alientan un romanticismo de carácter antindustrial sobre algo perdido y que se puede recuperar, y también sustentan la idea de la protección y del desarrollo turístico y actividades con criterios que no sobrepasen la capacidad de carga como punto crítico. De tal forma, en este travestismo capitalista o de industrialización sin chimenea, existe una búsqueda de lugares de alto potencial que pasan a ser incorporados como áreas de protección y control privado a través de compraventas, traspasos por parte del Estado a particulares o concebidos como parques nacionales, reservas o monumentos naturales, cuestión que nos permite hablar de que también el motor de la economía en la Patagonia está restringido más que muchos lugares por la protección a la naturaleza, generando una "neocolonización" como sostienen Núñez et al. (2014).
Es precisamente en la Patagonia donde la fórmula alcanza mayor complejidad, ya que también puede significar el reensamblaje naturaleza-sociedad a través de "la invención de una tradición" en los términos de Hobsbawn y Ranger (2002), con la agregación de elementos étnicos y denominaciones de origen que realzan un cierto arcaísmo, refuerzan una memoria episódica y de historias locales, de formas de interactuar y de prácticas económicas y productivas que son resituadas en un espacio simbólico y económico más amplio y con otros efectos simbólicos y económicos, tal como lo ha descrito García Canclini (1982) en "Las culturas populares en el capitalismo". Nos referimos por ejemplo, como la comuna de Río Ibáñez, que en su lugar de mayor concentración demográfica alcanza menos de 800 personas, se convierte en capital internacional del evento más importante de jineteadas de la Patagonia. Argentinos, brasileños, paraguayos, uruguayos y chilenos participan de la competición de domadura de potros, consistente en mantenerse con una mano por 8 segundos sobre el animal, acompañados por una audiencia de miles de visitantes que degustan corderos asados y otras comidas locales al ritmo de grupos musicales.

La discusión anterior, nos lleva al concepto de producción de rentas, remarcando el plural en la perspectiva de que los parques de conservación y el turismo son productores potentes de significados culturales, y a sostener que no es un problema de transitoriedad o de moda, sino que se trata de planteamientos que llegaron para quedarse, que comportan nuevos paisajes sociales y nuevas metáforas del lugar y que constituyen estrategias de relaciones, actitudes y comportamientos orientados por una agregación de signos que enriquecen los lugares (Oliva y Camarero, 2003).

Conforme a lo señalado, el artículo se ubica en el marco de la simbolización y en el valor otorgado a la excepcionalidad que ofrecen el espacio y paisaje patagónicos. La singularidad es lo que promueve el desarrollo de distintas conceptualizaciones como producciones de significado. Se propone como objetivo identificar y describir tres cambios fundamentales que se desarrollan actualmente en la Patagonia chilena, concentrándose en la zona Patagonia-Palena $\left(71^{\circ} 35^{\circ}\right.$ y $73^{\circ}$ $15^{`}$; $41^{\circ} 43,3^{`}$ hasta $43^{\circ} 44,1^{`}$ ) y Patagonia- 
Aysén $\left(71^{\circ} 06\right.$ y Océano Pacífico; 433` hasta 49 16), que representan modelos de apropiación, uso y reconfiguración del territorio tanto en su dimensión material como simbólica; los tres se sustentan sobre la conceptualización de la naturaleza como un commodity: 1) Migración por cambio de estilo de vida, 2) Parques de conservación mediante la venta de bonos de carbono y filosofía biocéntrica y 3) Economía de la experiencia y turismo.

En las siguientes páginas se presentan resultados de una investigación con enfoque cualitativo y sincrónico, basado en una estrategia de triangulación de datos provenientes de diferentes fuentes: primarias a través de entrevistas realizadas con informantes clave, y secundarias como datos estadísticos, bibliografía, literatura, y documentos de servicios públicos.

\section{Migración por cambio de estilo de vida: del arcaísmo rural a la neocolonización}

La idea del proceso migratorio por cambio de estilo de vida o "amenidad" corres- ponde a la "migración de personas desde grandes metrópolis a ciudades pequeñas o pueblos en el interior" (González, 2011: 1102), los que pueden ser nacionales o extranjeros. Esto, parece estar muy bien reflejado por Jon Krakauer (2013: 87) en términos de incitación a transgredir los límites de la propia vida: "Solo tenemos que ser valientes, rebelarnos contra nuestro estilo de vida habitual y empezar a vivir al margen de las convenciones". La sentencia parece resumir un híbrido entre el incorruptible Capitán Nemo, de Verne, el que se exilia de toda civilización y corta los lazos con la tierra; la renuncia de Tolstoi al mundo y a las tentaciones; Jack London y la aventura, y Thoureau y su vida en los bosques y su desobediencia civil. En esta apuesta, en toda la extensión del destino Patagonia (véase Figura $N^{\circ} 1$ ), hay impulsos muy íntimos que concurren a recuperarse en la más bella historia de la tierra: humanizarla y humanizarse.

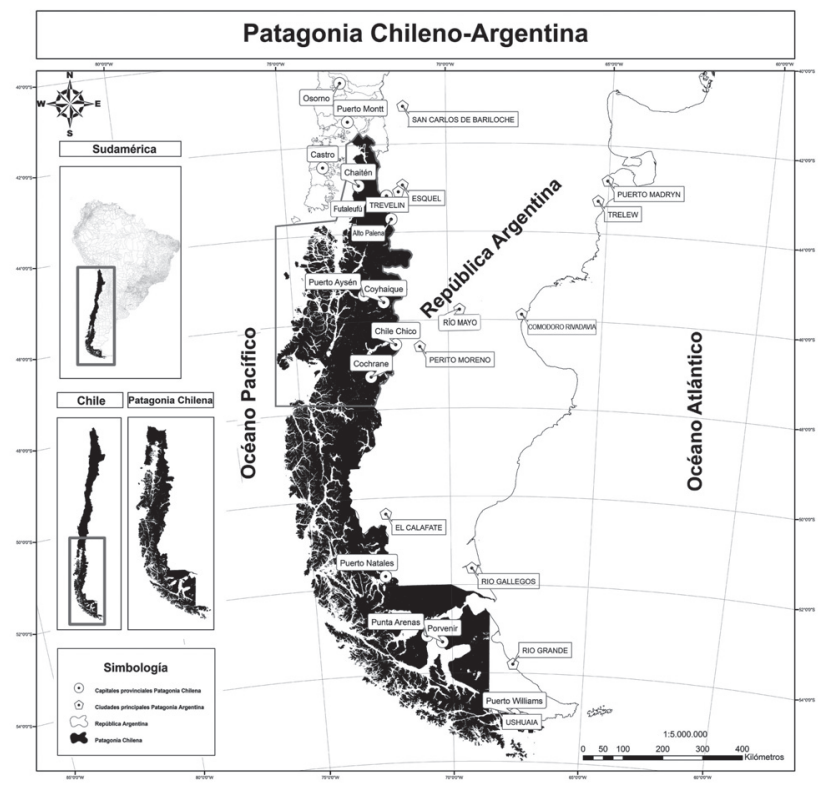

Fuente: Elaborado por Álvaro Huirimilla. 
Los migrantes por amenidad (Zunino et al., 2010) pueden caracterizarse como aventureros, neorrurales o neocolonos, muchos extranjeros, provistos de capitales económicos, sociales y culturales citadinos (idiomas, experiencias de vida en otros países, títulos), que habiendo sido turistas, regresan ya no de visita a un lugar que provee de alta calidad ambiental, sino "para constituirse en habitantes del mismo" (González, 2011: 1104), ya que están en busca de una nueva escala de relaciones sociales y con el paisaje. Si en la tradición moderna la ruralidad representó principalmente el atraso -tanto desde el punto de vista del pensamiento, las comunicaciones y la dotación y oferta de servicios- en la Patagonia reciente la oposición rural/urbano fija la oposición entre la tradición y el vértigo urbano, entre la lentitud y la aceleración para controlar la propia vida, por lo que se trata de un proceso migratorio inverso, que pone al frente la denuncia sesentera de Jane Jacobs (1967) de la "muerte y vida en las grandes ciudades" ${ }^{\prime 7}$.

Esta idea se refleja en los siguientes testimonios recogidos en Futaleufú, provincia de Palena:

"Estuve mucho tiempo buscando una posibilidad en el servicio. Yo conocía Futaleufú desde hace tiempo. Vivíamos con la familia en Temuco, que inicialmente era un buen lugar. Después vinieron dos cuestiones que se hicieron insoportables: la congestión y la contaminación. De aquí esperamos no movernos, Ilegamos para quedarnos" (Hombre, 40 años).

"Yo soy de Santiago. Mi primera escala fue en Puerto Montt donde trabajé profesionalmente. Soy Trabajadora Social. Pero Puerto Montt estaba muy loco. Futaleufú es pequeño, la gente te saluda, te da las buenas tardes y las gracias; te piden las cosas 'por favor'. Lo que se perdió en Puerto Montt es el sentido de comunidad. Aquí la persona más rica y la más pobre van a la misma escuela; aquí, se vive con poco... uno tiene la sensación de segu-

\footnotetext{
7 No desconocemos que esto constituye una paradoja, en la medida en que la tendencia local es al despoblamiento de las zonas rurales tal como lo hemos constatado en el trabajo de campo y en el manejo de información secundaria provisto por el Instituto Nacional de Estadísticas (INE).
}

ridad. Aquí uno puede tener un proyecto con hijos. Mientras tengas leña todo funciona, especialmente cuando estás construyendo un proyecto de vida. Yo espero con ansia el invierno; puedes pensar y leer. Mi marido es norteamericano y se dedica a enseñar inglés, que es una necesidad acá y es una ventaja" (Mujer, 32 años).

En la comuna de Palena, otro testimonio se ubica en la misma dirección: "Soy profesora. Llegué a mi primer trabajo y sin conocer a nadie. No fue fácil al principio, reconozco. Pero descubrí el valor de las relaciones cercanas; vivo en el campo, tengo hijos y soy feliz".

Se suma a estas percepciones el de una funcionaria pública en Chaitén: "a pesar de la destrucción de Chaitén por la erupción del volcán, se presentó una oportunidad de trabajo que no pude desechar. Tengo trabajo, seguridad y un hijo feliz. Todo se alineó para la familia. Mi esposo es mecánico, empezó de cero y ahora tiene su propio taller. Nada nos falta. No pensamos volver".

Un extranjero con 15 años de avecindamiento en una parcela rural, y considerado como un emprendedor por sus vecinos, señala:

"Yo supervisaba el funcionamiento de chimeneas para evitar incendios y contaminación en Alemania. Era un trabajo bastante simple y rutinario, porque tenía que ir mirando todas las casas. Me vine a este rincón después de buscar más de un año un terreno; tengo unas pocas ovejas, produzco cerveza de manera muy artesanal y un poco de turismo rural. De eso vivo. Todo es trabajo, todos los días; no es fácil moverse a otros lugares. Pero aunque no tenga dinero, como, duermo la siesta, veo alguna película en el computador, y ya no puedo volver a mi país ni a la ciudad. Soy libre".

Los testimonios apuntan a cuestiones que se repiten: cansancio, hastío, superficialidad de las relaciones en la ciudad y búsqueda de nuevas oportunidades y sentidos. Por ello, la cuestión de la escala de relaciones sociales y con la naturaleza se vuelve vital, ya que se trata de forasteros que buscan ser aceptados dentro de esta nueva orientación cultural y cohesionarse con la comunidad, y ello impli- 
ca inversión en primera o segunda vivienda, lo que por sí mismo constituye un proceso de encantamiento al inaugurar un nuevo espacio propio y de intimidad. Asimismo, la decisión conlleva una cierta osadía en cuanto es tremendamente abierta desde la perspectiva de la conquista de un nuevo espacio social; en este se juegan habilidades para enfrentar la repetición sin agotarse, la sobrevivencia básica, diferente a los riesgos urbanos y donde casi todo se encuentra resuelto.

Un médico avecindado en Futaleufú refleja una expectativa de integración local: "para ser de Futaleufú, hay que tomar mate, bailar chamamé y bajar el río en balsa".

En estos testimonios e ideas existe una reconceptualización de valores e intereses personales asociados a un renunciamiento del estilo de vida urbano y sus riesgos, en la perspectiva de Beck (2006), y el malestar urbano en la de Jacobs (1967). El esfuerzo se concentra en la búsqueda de una vida más auténtica, más pausada y la posibilidad de un cambio existencial con un nuevo abanico de valores con los cuales vivir, sin perder de vista la importancia que tiene internet como parte de la vida cotidiana. En este sentido, cuando se valoriza el río, el sendero, la tranquilidad, el reconocimiento de las fortalezas de cada una de las estaciones con sus paletas de colores y letanías, hay un giro de prioridades y un avance hacia una axiología de orden posmaterialista en la idea desarrollada por Ronald Inglehart (1998), sin renunciar a los estándares de la sociedad de la información y globalización, de búsqueda de más autoexpresión, privilegiando la salud en sentido amplio, volcando la mirada sobre un bienestar psicológico y existencial.

Se trata de una escala más humana de vida, de una mutación simbólica y de apreciación de detalles, donde la cercanía a la naturaleza se convierte en un nuevo referente que refleja un alejamiento del énfasis en la eficiencia económica, la autoridad burocrática y la racionalidad científica. En este sentido, como señalan Hidalgo y Zunino (2012: 10), se trata de "prácticas que podrían estar en la frontera de los movimientos contestatarios al sistema capitalista imperante en la actualidad, anclado en manifestaciones posmodernas inmersas en la globalización neoliberal".

En los migrantes por amenidad existe un cambio significativo en la percepción, ya que hay una representación social de la naturaleza que condensa una reconceptualización del tipo de relaciones sociales y con la naturaleza deseable, y una organización de respuestas y conductas hacia ellas. Así, se avanza hacia una apreciación de los colores, los ríos de flujo libre, los lagos, las montañas, y una alta valoración de la flora y la fauna como elementos irrenunciables; también se descubre que son importantes el paso de las estaciones, de nubes negras y cargadas a los cielos límpidos, ya que el fuego y la intimidad conectan con el tiempo existencial, imponiéndose por sobre el tiempo cronológico.

Dos testimonios refuerzan estas ideas: "Para mí, ojalá esta zona permaneciera siempre así, con la conectividad [vial] que tenemos ahora".

\begin{abstract}
"Muchas veces se ha hablado de la conectividad. Pero, para los microempresarios turísticos, la conectividad, más que un problema, es un plus para su negocio enfocado a turistas de intereses especiales. Trabajamos con quienes buscan esta clase de destinos que podemos llamar inalterados y desconectados de la modernidad" (Operador turístico en Futalefú).
\end{abstract}

\section{Los parques de conservación: entre el carbono y la filosofía}

Los parques nacionales en el sur de Argentina tuvieron una función estratégica y política: marcar el territorio nacional. Para ello, la evaluación por parte de autoridades argentinas sobre hitos fronterizos lábiles, de uso de recursos locales por parte de población evaluada como "extranjera", transfronteriza o binacional, indígena y no indígena, hace que la figura del parque nacional se convierta en una estrategia temprana de fijación de límites, ya que estar en uno de ellos implica estar en Argentina. La medida se complementa con ordenanzas de tipo arquitectónica en 1935, que decantan en la idea de la "Suiza argentina", ya que se establecen los formatos estilísticos de construcción tirolesa que llegan hasta nuestros días y son recepcionados como arquitectura típica, lo que por cierto confiere identidad a las ciudades y poblados y a todas las instituciones públicas.

Extensivamente, los parques de conservación corresponden a un cambio tardío en las formas de protección de la naturaleza o de espacios amenazados o ecosistemas vulnerables por la acción antrópica o de otras especies 
introducidas. Corresponde al aislamiento de determinados lugares bajo control privado, con el fin de proteger los distintos ecosistemas y especies. Se trata también de áreas protegidas que impiden el avance de especies exóticas. Ello implica, siguiendo a Rodríguez y Requena (2014), un oxímoron, es decir, la figura contradictoria entre aquello que siendo natural se le impone un límite y una artificialidad, ya que por definición un parque es algo cerrado y acotado.

El concepto de parque natural o de conservación tiene como elemento central la figura de una amenaza y su perímetro -sea definido en términos políticos, ambientales o simbólicos- implica una limitación de prácticas posibles y usos de lo que el lugar contiene. De este modo, por una parte, el parque genérico concentra un interés específico que puede ser estatal o privado $y$, por otra, efectos locales sobre las comunidades o poblaciones aledañas o vinculadas a través de alguna actividad económica productiva que ven amenazadas sus estrategias de subsistencia, como la forestal o ganadera. Así, según Rodríguez y Requena (2014: 169), "la declaración de un área protegida supone no solo una nueva organización y apropiación de recursos, sino también una definición del espacio".

En Chile, este concepto de parque privado se introduce en los años 90, cuando algunos conservacionistas norteamericanos como Douglas Tompkins (socio de Esprit), Yvon Chouinard (dueño de Patagonia Inc.) y Alan Weeden compran las primeras 500 ha de bosque de araucarias en las cercanías de Pucón, con el predio Cañi. Luego, siguieron 17.000 hectáreas y sumaron 230.000 que costaron unos US\$ 7 millones. Las iniciativas privadas de conservación llegarían a 308 en la actualidad (Langman, 2014). Lo importante es que no se compra terreno, sino esencialmente ecosistemas y lo que se implementa es un modelo: un parque privado-público de conservación. Este modelo es de conservación de especies vulnerables y endémicas (huemules, guanacos, especies marinas, bosques templados), de reforestación en los casos de algún incendio en el pasado y de contención de iniciativas forestales y empresas extractivistas. Para ser coherentes, sus obras interiores y perimetrales se implementan con maderas de árboles muertos.

Bajo esta figura existen las siguientes Fundaciones: Pumalín, para el parque del mismo nombre de Douglas Tompkins; Futuro, para el parque Tantauco del expresidente Sebastián Piñera; Huilo Huilo, con el parque del mismo nombre del empresario de ecoturismo Víctor Petermann; Karukinka, de Henry Paulson. Hablamos del territorio chileno con una extensión que va desde Pucón a Tierra del Fuego, desde la isla de Chiloé al límite con Argentina.

Sin embargo, en la práctica, esta apropiación territorial proteccionista da cuenta de problemas de Estado y gobierno sobre la presencia en estas tierras; las políticas de colonización y de agenciamiento; el centralismo y los actores políticos, privados y locales que sostienen miradas territoriales diversas y proyecciones disímiles para estos lugares. Estos entrampamientos que llevan a la creación de parques privados surgen porque los sistemas de protección del Estado no funcionan de manera tan efectiva, lo que se encuentra dado esencialmente por la falta de recursos en las instituciones como la Corporación Nacional Forestal $(\mathrm{CONAF})^{8}$, para operaciones e infraestructuras, de personal especializado para desarrollar investigación, la jeraquización de sitios de interés para la conservación biológica entre "urgentes", "importantes", "de interés" e "interés específico"; las diferencias entre un Parque Nacional, una Reserva Nacional y un Monumento Natural, y la falta de compatibilidad entre cuerpos legales de minería, aguas, concesiones marítimas y de navegación (Muñoz et al. 1997). Asimismo, por cuestiones de derecho de propiedad, algunos lugares de interés no pueden integrase al Sistema Nacional de Áreas Protegidas (SNASPE) que busca la representatividad ecosistémica; también, para las áreas bajo protección y prioritarias, se carece de "información sobre la dinámica precisa de cada ecosistema y su flujo de intercambio de materiales, energía e información genética con las áreas circundantes" (Muñoz et al., 1997: 91).

Lo señalado, diagnosticado también en lo que fue la edición del "Libro Rojo de los Sitios para la Conservación de la Diversidad

\footnotetext{
8 Por ejemplo, en la provincia General Carrera, la Reserva Jeinimeni colindante con la Estancia Valle Chacabuco del ecologista Douglas Tompkins, en la que este pretende desarrollar un corredor ambiental al unir ambos predios bajo una donación al Estado, la institución tiene un presupuesto anual de 6.000.000 y no cuenta con un programa de manejo, por lo que no pueden estimar la capacidad de carga posible de visitantes (Registro de campo en Jeinimeni y en oficinas CONAF en Chile Chico, agosto 2014).
} 
en Chile" (CONAF, 1996), es lo que atenta contra la generación de conocimiento, las decisiones políticas, la voluntad de privados y el sector público, impidiendo una comprensión más holística sobre la biodiversidad y la extensión de los ecosistemas. Esto, especialmente cuando aplicamos el criterio de ecorregión, entendida como una unidad de importante densidad de tierra o agua, en la que convergen geográficamente concentraciones de especies, comunidades naturales y condiciones ambientales.

\section{Modelo Patagonia Sur: disminuyendo la huella de carbono}

Este modelo corresponde al establecido por Patagonia Sur, orientado al desarrollo inmobiliario y de venta de bonos de carbono, lo que se delinea en una publicación del ámbito de los negocios. El encabezado de la entrevista al empresario Franco Valdés, en Magazine Business Chile (14/7/2010) señala que Patagonia Sur es: "Una empresa de riesgo compartido chileno-estadounidense que ofrece a los inversionistas preocupados por el medio ambiente una oportunidad única en la Patagonia para comprar prístinas áreas silvestres, mientras que al mismo tiempo las protegen y desarrollan de una manera sustentable". Esto, debemos decir, se ubica en un ámbito específico de consideración simultánea de "la estabilidad política y económica, y las leyes claras sobre la posesión de propiedades" en Chile y de la Patagonia como mercancía y como marca, lo que constituye según Dimitriu (2002) un econegocio al incorporar los campos, ríos, lagos, bosques, glaciares, mallines y estepas a una fórmula de ecocorretaje.

Es un buen negocio, se señala en la misma entrevista: "Creo que lo que hemos creado aquí es un concepto muy innovador y vanguardista para la conservación [...] nuestros clientes pueden decir estoy haciendo lo correcto, pero al mismo tiempo esto es bueno para mi cartera". Así, el rentismo se produce a través de un modelo de negocios donde los inversionistas no deben estar realizando aportes permanentes, sino que se encuentran de forma continua capturando recursos, ya que un bono de carbono al año 2010 valía US\$15 y un árbol capturará entre 0,25 y 0,4 toneladas de carbono en el futuro (Magazine Business Chile, 2010).

La empresa propone la creación de un fondo de US\$ 30 millones, con cuya estrate- gia se produce simultáneamente la conversión de la tierra en suelo y objeto de especulación y control inmobiliario, y en ajuste a un rentismo sin trabajadores y sin organización ${ }^{9}$. Los inversionistas, quienes pagan US\$ 350.000 por acción, poseen los activos y la totalidad de los flujos provistos por el negocio, en el que se plantarán unos 500.000 árboles y se estipula que si invierten un millón, al cabo de 10 años recibirán dos.

Con oficinas en Estados Unidos y Chile y con presencia en la $\mathrm{X}$ y XI región; además de cuatro organizaciones con distintos ejes programáticos que complementan su estrategia de negocios: Centro MERI, la Fundación Patagonia Sur, Reforestemos Patagonia y Fundación Tierra Austral. La compañía Patagonia Sur cuenta con siete extensos predios: en Palena (río Palena, 55 ha), Valle de California (3.200 ha), Futaleufú (lago Espolón, 244 ha), Melimoyu (16.059 ha), Los Leones (522 ha), Jeinimeni (1.289 ha), Caleta Tortel (1.435 ha). Se trata de una empresa dedicada al negocio inmobiliario y a las compensaciones de $\mathrm{CO}_{2}$ para mitigar los efectos de los Gases de Efecto Invernadero (GEI), por lo que pone sus ejes narrativos en la conservación vía ampliación de las superficies de bosque nativo y el desarroIlo sustentable (http://www.patagoniasur.com/; Langman, 2014: 21). Ello significa una estrategia simultánea de protección y de explotación económica que incluye la venta de propiedades a inversionistas mundiales a quienes les ofrece "servidumbres voluntarias"10 y la posibilidad de realizar usos agrícolas no intrusivos, ecoturismo y la construcción de su vivienda. La característica es que el negocio se desarrolla en "propiedades escénicamente extraordinarias y ecológicamente valiosas", donde lo privado es una pequeña porción y el 85\% son tierras comunes y de reserva (http:// www.patagoniasur.com/).

La oferta para los potenciales compradores incluye la posibilidad de construcción de una casa nueva y al acceso como socio a miles de hectáreas disponibles, protegidas, conserva-

\footnotetext{
9 Asimismo, no desconocemos que, como instrumento, la venta de bonos de carbono extiende el derecho a contaminar en otros lugares.

10 Una servidumbre de conservación consiste en que un vecino acuerda el libre paso de otro por su propiedad, hacia un río, un lago o un bosque, generando un proceso de confianza, protección y acceso de bienes comunes.
} 
das y otras replantadas que pasan a ser parte de los predios. Los inversionistas están habilitados para desarrollar sus propios emprendimientos a través de la construcción de hoteles de baja ocupación, desarrollar prácticas ecoturísticas e incursionar en el kayak de río y lago, cabalgatas, promocionar el avistamiento de aves, fauna marina y terrestre, trekking, senderismo, ciclismo de montaña y pesca deportiva. Las limitaciones para los propietarios y comuneros son no producir alteraciones del paisaje ni desarrollar actividades industriales; tampoco la intervención de ríos ni lagos. Asimismo, las propiedades deben construirse en armonía con el entorno y deben ser sostenibles, de bajo consumo energético o con sistemas alternativos, y construcciones con materiales de bajo impacto. El aseguramiento de que las condiciones se mantendrán en el futuro, respecto de bienes, comunes está dado por la formación de la Fundación de Conservación Tierra Austral (Tierra Austral Land Trust), la que sin fines de lucro y signataria del territorio bajo protección, administra el 85\% de las tierras comunes.

El modelo tiene como eje la disminución de la huella de carbono, por lo que se enlaza con los efectos de gases invernadero como consecuencia de la deforestación y la ampliación de las fronteras agrícolas -que en nuestro país ha aumentado en un $166 \%$ en los últimos 14 años- al considerar que un ciudadano produce entre 4 y 5 toneladas al año de $\mathrm{CO}_{2}$ (http://www.patagoniasur.com/). Como es sabido, internacionalmente esta estrategia privilegia la recuperación de las tierras en cualquier parte del mundo a través del fomento a la plantación de bosque nativo, en este caso coigües, ñirres y lengas en el valle de California en Palena, y en lugares donde algún incendio o intervención antrópica ha dañado un bosque, este reforestado con la misma especie. El objetivo de conservación en la Patagonia chilena es porque en ella existe la más importante reserva de bosques templados del planeta, lo que hace factible revertir la producción de $\mathrm{CO}_{2}$ que se encuentra en la atmósfera y la ampliación del hábitat para las especies nativas. En este modelo desarrollado por Patagonia Sur, al 8 de junio de 2014, se indica el plante de 90.402 árboles nativos con una captura de 45.201 toneladas de $\mathrm{CO}_{2}$, y la creación de 7 bosques (http://www.patagoniasurco2.com/).

Indican los gestores del proyecto que "además de absorber dióxido de carbono, el programa de reforestación de Valle California, que es el piloto, beneficia a la ecología y economía rural, ya que controla la erosión de la tierra, fortalece las comunidades de plantas nativas, reduce el número de especies no nativas e invasivas, mejora el hábitat para la fauna de la región y crea nuevas fuentes de trabajo sustentable para los residentes locales" (http:// www.patagoniasurco2.com/).

Entre sus clientes se encuentra la afamada marca de vehículos Land Rover, que plantea así su estrategia de mitigación: "Todos los autos emiten dióxido de carbono, pero como Land Rover estamos compensando todas las emisiones durante su primer año de uso... Para ello, compramos Bonos de Carbono a una empresa que se Ilama Patagonia Sur. Ellos plantan bosque nativo en la Patagonia chilena como parte del Proyecto de Reforestación y Biodiversidad" (El Mercurio, 2012).

\section{El modelo Pumalín y de la estancia Valle Chabuco: filosofía biocéntrica}

Persiste en la Patagonia, como herencia del planteamiento socioecológico en los años 60 , un análisis cuyo centro es una preocupación social, política y científica ubicada en una ruptura paradigmática respecto de los valores dominantes asociados al consumo y al estilo de vida destructivo y opulento de las sociedades industrializadas modernas. Este se sustenta en una crítica al antropocentrismo en sus privilegios y una reubicación de los seres humanos en una posición equivalente, en términos de valor, ante otros seres como las plantas y los animales. En este sentido, existe una afirmación del derecho de los otros a existir, lo que constituye una ampliación de los límites de la concepción de comunidad, la que es llevada a todos los sistemas naturales. Así como en el campo de la antropología el reconocimiento a la pluralidad de opciones y respuestas culturales se constituye en el núcleo de la aceptación de los límites de la propia vida, el reconocimiento de la infinita diversidad ecosistémica se constituye en una ampliación del propio campo de comprensión de la vida.

El fundamento de esta consideración se encuentra en Aldo Leopold (2007: 24-29), quien plantea que es necesario allanarse a una concepción más amplia de la ética, superando la relación entre humanos y la relación entre humanos e instituciones. En este 
sentido, señala el filósofo que debe haber una preocupación por una "ética de la tierra", porque una ética "en términos ecológicos es una limitación a la libertad de acción en la lucha por la existencia". Esta limitación y cambio de giro en el privilegio antropocéntrico, por una parte, constituye una posibilidad evolutiva en términos humanos y una necesidad ecológica; por otra, una interrogación personal que distingue las necesidades vitales de los deseos y un activismo espiritual a favor del bienestar de otras especies, ya que el proceso expansivo de la conciencia es de comprensión de las vidas en plural.

La iniciativa más clara en esta dirección en territorio chileno corresponde al proyecto Parque Pumalín, de 290.000 hectáreas, en la provincia de Palena. "El Proyecto Pumalín incluye campos orgánicos restaurados de una fuerte degradación ecológica, iniciativas sociales que promueven una vida sana y valores de conservación en las comunidades vecinas, y campañas de activismo que abarcan los temas de conservación más grandes de la región. Por más de dos décadas, este método de conservación ha permitido que el proyecto extienda su impacto mucho más allá de los límites del parque" (http://www.parquepumalin.cl/).

El parque expresa una contención de los avances del mundo forestal, lo que se retrata en la publicación del libro "La tragedia del bosque chileno", en el que su promotor Douglas Tompkins (1998), escribe el prólogo titulado: "El futuro y la esperanza". Aquí señala sus preocupaciones por la protección de los bosques y sus acciones a favor de la conservación; comparte sus relaciones internacionales con pensadores, activistas y científicos; instala su crítica a los intereses creados, pero también su esperanza y optimismo respecto de la reversibilidad de la lógica industrial hacia una sustentable que incluya la conservación de la biodiversidad. Pregunta: ¿Por qué llegar hasta el borde mismo, si existen soluciones desarrolladas en los mismos países que cometieron profundos errores?

En este prólogo, es categórico respecto de dos temas: 1) El reconocimiento de que él fue un empresario, que conoce la economía por dentro, por lo que hay una crítica a esta, y 2) una categórica sentencia: "Uno debiera recordar siempre que los bosques antiguos o primarios (Old Growth Forest) no son un recurso renovable dentro del marco convencional del ciclo de los tiempos económicos" (1998:40). De esto, sin mencionarlo, se deja entrever su concepción filosófica de la Ecología Profunda, la que en su primer postulado señala: "el bienestar y florecimiento de la vida humana y la vida no-humana tienen valor intrínseco. Estos valores no son dependientes de la utilidad o los propósitos humanos" (Naess, 1995).

La sabiduría está en acercar a los seres humanos a la naturaleza. Pero, se antepone el valor de la existencia de los otros seres al uso potencial que podamos hacer los humanos de ellos. Por esto, el Parque Pumalín contiene una limitación de uso: no cortar, no pescar, no alterar, no encender fuego. Se trata de un modelo conservacionista duro y restaurador de los ecosistemas originales y de eliminación de lo exógeno, descreído de recetas políticas ubicadas dentro de los modelos de desarrollo, ya que las considera incapaces de satisfacer las necesidades básicas de aquellas poblaciones que disponen de pocos recursos y mantiene un escepticismo respecto de que con la tecnología puedan mejorar las condiciones ambientales (Silva, 1999).

Una extensión y ambición de este concepto se encuentra, desde el 2004, en el proyecto Estancia Valle Chacabuco, emplazado en la provincia Capitán Prat, con una extensión de 78.000 ha. Este predio ubicado en una de las exclusivas zonas estepáricas, se reconstituye hacia la fórmula de parque de conservación después del fracaso de las iniciativas más importantes ligadas a la ganadería extensiva, la que es considerada esencialmente por sus externalidades como un "modelo de exportación de suelos". Esto significa que el sobrepastoreo ovejero y vacuno dejó un pasivo ambiental in situ ${ }^{11}$ y las potenciales ganancias abandonan el ámbito local, transformando lo ganadero en la actualidad en una economía de subsistencia, ya que no hay mercados, no hay praderas y no hay vías que faciliten la conectividad para sacar los productos y hacer "negocios rentables".

De este modo, la Fundación Conservación Patagonia reconsidera los términos de la ecuación costo-beneficio, Ilevándola a la de una oposición entre un parque o una economía de subsistencia, ya que el fracaso de los grandes

\footnotetext{
11 Su estado la ubica en el Libro Rojo de los Sitios Prioritarios para la Conservación de la Diversidad en Chile (CONAF, 1996) y una prioridad por existir en ella la mayor biodiversidad de la Región de Aysén.
} 
productores reduce a la población ligada al trabajo ganadero a una condición muy precaria. Su administrador, indica sobre este punto:

"En Chile, me atrevería a decir que prácticamente casi la totalidad de las áreas silvestres protegidas son reconversión de espacios productivos o áreas descarte o de desecho... con este proyecto aspiramos a la creación de un gran parque de 250.000 hectáreas, como sería el futuro Parque Nacional Patagonia, suma de la
Estancia Valle Chacabuco y las reservas nacionales Jeinimeni y Tamango; se podría construir un gran corredor [de protección y restauración]. Para el Estado, el turismo es retorno e inversión para la región a bajo costo, y para el proyecto conceptual de la Fundación Conservación Patagónica el activo es el retorno ambiental, porque todos cuidamos. Nosotros no lucramos, con las donaciones hacemos filantropía. Los tiempos son lentos, pero avanzamos en el proyecto".

Figura $\mathrm{N}^{\circ} 2$

Reserva Nacional Jeinimeni

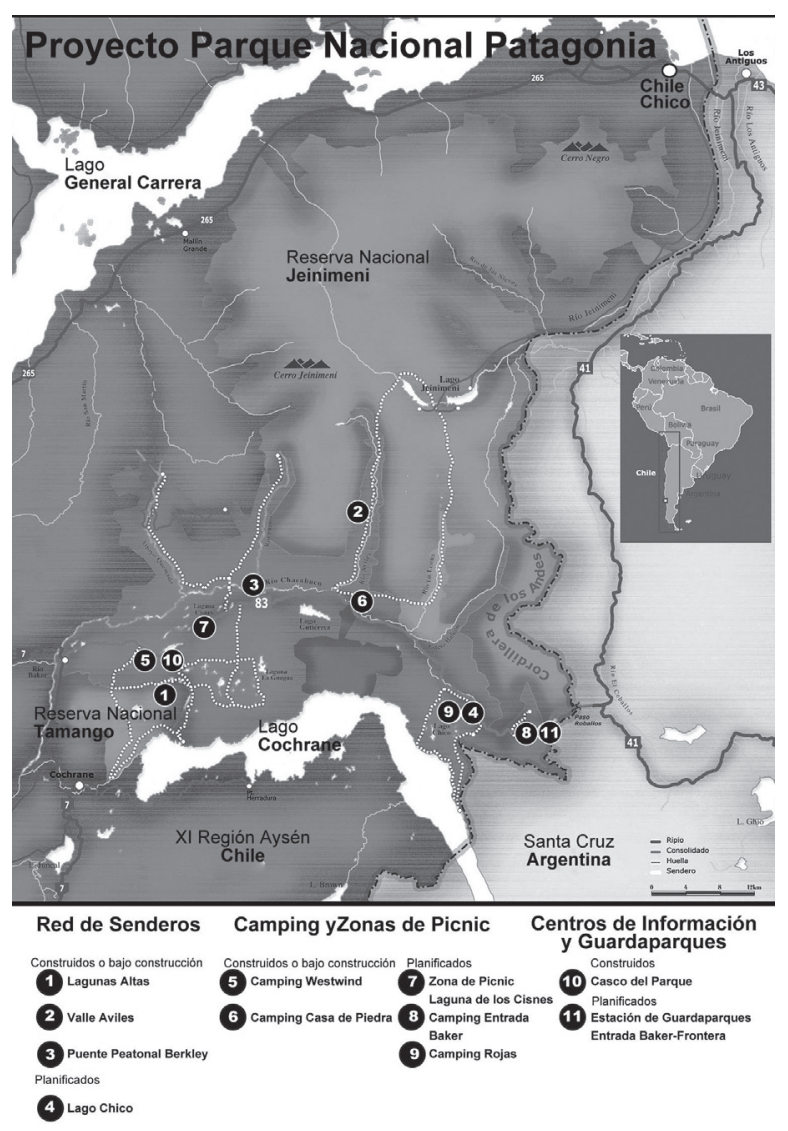

Fuente: Elaborado por Manuel Astudillo. 
Conforme a la filosofía descrita más arriba, lo importante de este proyecto es alcanzar el mayor umbral de disclimax, es decir, ya que como no es posible recuperar el estado de máxima estabilidad y eficiencia en la sucesión ecológica, se trata de generar un modelo de recuperación limitando los usos históricos de ocupación ganadera, controlando ordenadamente el ingreso de visitantes, eliminando conceptualmente las especies introducidas y favoreciendo la recuperación de la pradera estepárica y los animales endémicos. Con ello, señala el administrador, en este esquema interesan dos tipos de retorno: a) social, y b) ambiental. Esto, porque: 1) No existen áreas estepáricas protegidas en Chile, y este proyecto en curso iría en esa dirección, 2) están los huemules como objetivo, el ciervo endémico más austral y en peligro de extinción por la competencia de las vacas y las ovejas, 3) la pretensión de visibilizar la región en el mundo y aumentar el ingreso a esta a través de este parque, y 4) se busca la apropiación territorial del lugar en la nación como ocurre en Torres de Paine, donde hubo inicialmente rechazo y ahora está en el imaginario de todos los chilenos.

Se espera que de la elevación de la condición de reservas a parques nacionales se desencadene una defensa mediática de la naturaleza ante cualquier amenaza de desafectación de las áreas silvestres involucradas por parte del Estado o bienes de uso público, como ocurrió con el proyecto Hidroaysén. No existe discurso técnico ni político que pudiera contradecir el empoderamiento que podría provocar la defensa de la naturaleza a través del proyecto Parque Nacional Patagonia. Más aún, lo extraño es que un privado y extranjero puedan instalar un concepto nacionalista que asegure lealtad respecto de una parte del territorio.

Huelga decir, lo señalado no puede sino ser pensado en el contexto del importante crecimiento durante las últimas tres décadas del mercado de tierras a nivel mundial. Para el caso de la Patagonia argentina se estima que un 70 u $80 \%$ de la tierra se encuentra en manos de privados, y en Chile, a pesar de las cesiones de las grandes extensiones de tierra patagónica para la colonización con el trabajo ovejero en el pasado, y que dos tercios estarían en manos del Estado, los signos actuales hablan de inversiones importantes de empresarios y políticos especialmente en Patagonia-Aysén ${ }^{12}$, como puede apreciarse en la Figura $N^{\circ} 3$, más aún si se instala el criterio de localización de estas. Según Langman (2014:17), entre los principales propietarios se encuentran la familia Halley dueña de la cadena francesa Carrefour, los hermanos Benetton, Ward Lay, Ted Turner, Joseph Lewis, Stallone, DiCaprio, Douglas Tompkins, entre otros. Las fórmulas son diferentes: dueños individuales, fundaciones, universidades (Texas, Magallanes, Austral, Mayor), grupos ambientalistas, comunidades y negocios.

\footnotetext{
12 Aunque de los 9.000.000 de ha de Patagonia-Aysén una importante cantidad de tierra se encuentra en manos del Estado de Chile (Gobierno Regional de Aysén et al., 2005), destaca el control privado en todos los alrededores de Coyhaique, donde se encuentran las mejores praderas, los valles y todas las zonas que bordean los lagos y cursos de agua. No debe perderse de vista que aquí se encuentran los campos de hielo Norte $\left(4.200 \mathrm{~km}^{2}\right)$ y Sur $(16.800$ $\mathrm{km}^{2}$ ), y que si se restan estos la tenencia de la tierra cambia de manera importante en términos cualitativos.
} 
Figura $\mathrm{N}^{\circ} 3$

Tierras privadas, públicas y localización de los campos de hielo Norte y Sur

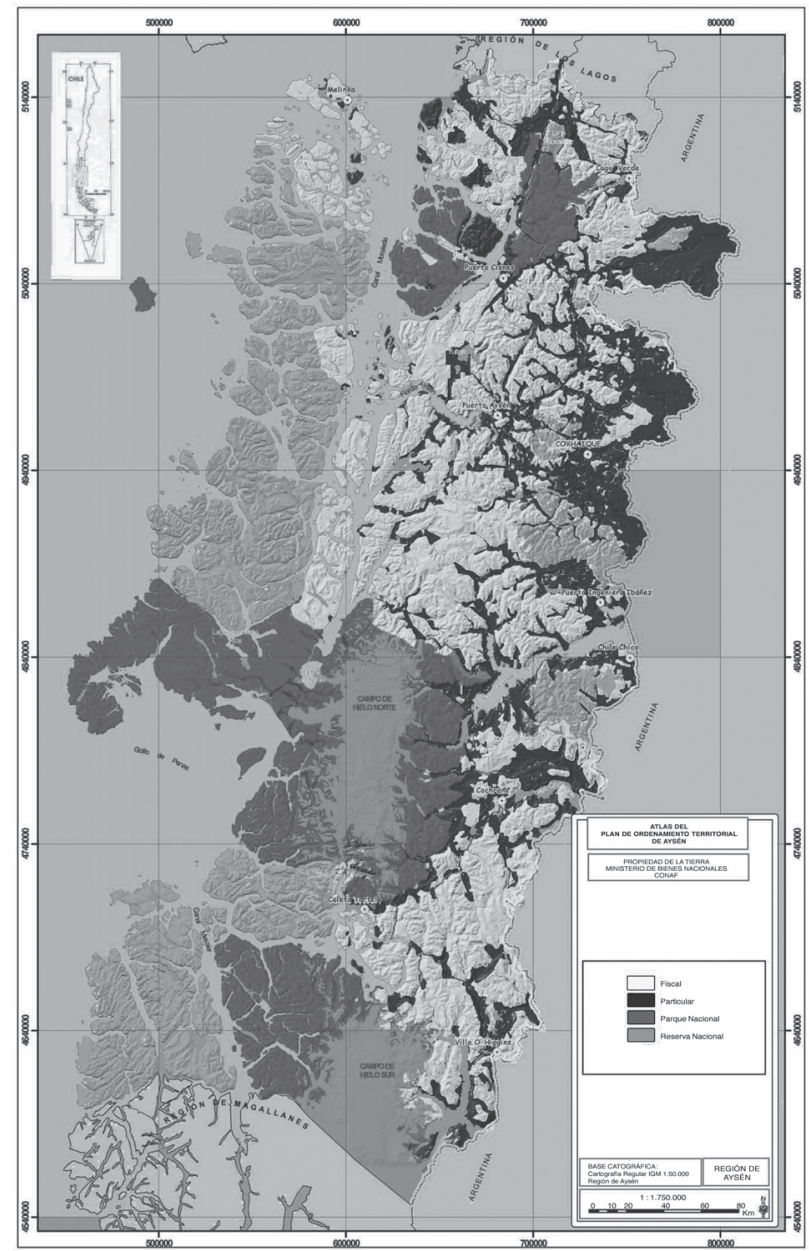

Fuente: Elaborado por Álvaro Huirimilla.

\section{El turismo y la economía de la experiencia: lo verde como commodity}

Nuestra tesis es que la Patagonia, por sobre todo, ofrece a quienes Ilegan desde cualquier rincón del mundo el estar de otra manera en relación con el tiempo y el espacio. Por ello, desde el punto de vista del turismo, lo que interesa es que el territorio ofertado sea competitivo en términos institucionales, tecnológicos, culturales y recreativos. Esto, como sostiene González (2011: 1107-1108), porque formalmente se trata de generar todas las condiciones para "incrementar el gasto turístico y aumentar la cantidad de visitantes a la vez que proveerlos con experiencias satisfactorias y memorables y hacerlo de manera que resulte rentable, promoviendo el bienestar de los residentes, y preservando el capital natural del destino para las generaciones futuras". En este caso, dos factores se encuentran en la base del destino: la alta calidad y diversidad ambiental reforzada por los parques de conservación y la posibilidad de entrar en contacto con otras formas culturales, lo que refuerza la apreciación de Moss 
(2006) de que estamos frente a un entramado donde lo significativo es la valoración del ambiente natural, la diferenciación cultural, el ocio, el aprendizaje y la espiritualidad.

Lo importante es que la voz Patagonia por sí misma y los soportes en los que se ha difuminado definen una condición que activa un imaginario formado por un conjunto de potentes imágenes, signos y símbolos relativos al paisaje y la libertad. Despliega una narrativa de ocupación pasada y presente con atributos ambientales positivos y características propias que llevan a la exploración del espacio abierto, al viento, a las montañas, los ríos y los océanos, a lo inhóspito y a lo desafiante. Pero, al mismo tiempo, indica una orientación económica dirigida a un tipo de "consumidor verde" que busca este diferencial de vivir y sentir distinto, que solo puede ser encontrado en lugares alejados y de difícil accesibilidad.

En su trama, se trata de una manera específica de incorporación de la naturaleza al mercado de consumo global, que implica una selección de quienes pueden participar al situarse fuera de la estandarización a través de "ofertas a la medida", ya que se crean lugares para audiencias específicas. En este sentido, hablamos de la conversión de lo natural en una mercancía de alto valor, en algunos casos del tipo "parque temático", con recorridos sugeridos por asentamientos de grupos étnicos, estancias ovejeras, sitios identificados con viajeros, paisajes y decoraciones que mezclan rusticidad y lujo en estancias (y lodges) que son reacondicionadas y pensadas especialmente como alojamientos para recibir a un público extranjero de altos ingresos, que busca "desaparecer del mundo" y "pasar inadvertido". En otras fórmulas, la Patagonia es ofrecida para la práctica de deportes extremos o de elite en escenarios privilegiados, que implican el enfrentamiento a cuestiones memorables como bajar el río Futaleufú en balsa o kayac; también se induce a las caminatas, la observación de flora y fauna, la pesca deportiva o, simplemente, apreciar el silencio y tener el viento por compañía.

Una arista de este proceso de comercialización in situ se expresa en la idea de ecoturismo o turismo responsable definido por actividades poco invasivas, lo que por una parte lleva a la idea de lo sustentable, es decir, lo que "la conciencia ecológica exige" y, por otra, a una asociación a turistas de países con altos ingresos que pueden acercarse a una oferta única, pues en los términos de Pine y Gilmore (1999) no se trata de la venta de tangibles o intangibles, sino de tener experiencias.

El modelo apunta a activar una comunicación efectiva con el paisaje para quienes tengan "buen gusto y prácticas de buen vivir". Esto es, que pueda ser propicio para el aprendizaje y transmitir evocaciones y asociaciones míticas y místicas, sacralizando la naturaleza y Ilevándola a lo más íntimo del yo. En esta modalidad, la Patagonia condensa un lugar donde comienza la aventura y la posibilidad de acceder a rincones y parajes únicos que alojarán en la memoria para toda la vida, ya que los alerces de miles de años, las capillas de mármol o los campos de hielo Sur y Norte son únicos. Pensada desde la "economía de la experiencia" y como "forma de conocimiento" en los términos de Pine y Gilmor (véase Figura $N^{\circ} 4$ ), para quienes recorren su territorio se trata antes que nada de descubrir, despertar sensaciones y emociones provistas por el paisaje, por la inmersión en la vida local y por la ausencia de tentaciones modernas. Todo conduce a vivir una experiencia superlativa de "estar donde aún no ha llegado nadie"13, por lo que la presencia ante la naturaleza se convierte en la posibilidad de la transformación de sí mismo, en el límite de la conversión hacia una nueva vida.

\footnotetext{
13 Registro de campo realizado en Futaleufú, en octubre de 2012.
} 


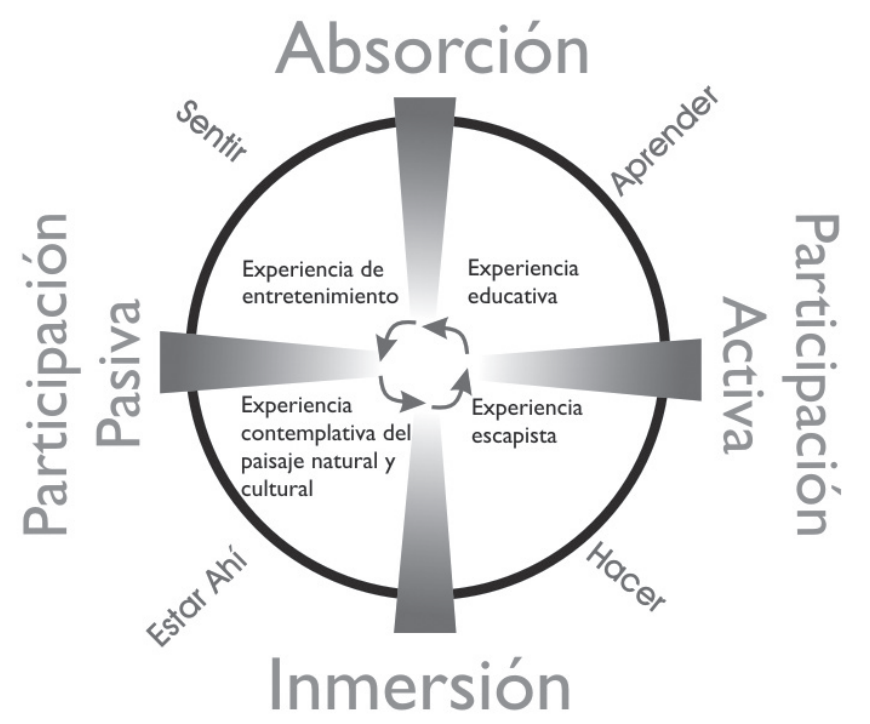

Fuente: Elaboración propia adaptado de Pine y Gilmor, 1999.

Concordamos con los autores Pine y Gilmor (1999) en que la experiencia se enmarca dentro de una nueva oferta de la economía de mercado. La "economía de la experiencia" está asociada a una persuasión y a un involucramiento que se encuentra más cerca del teatro, es decir, del sentir por los juegos de roles y los decorados existentes, ligados a una anatomía de lo verde y lo rústico que implica experiencias escapistas (ser un/a desconocido/a), educativas (enfrentarse a actividades desconocidas), contemplativas (apreciación de la naturaleza) y de entretenimiento (los distintos deportes). En este sentido, como sostiene Joan Buades "la globalización crea una casta unificada y estandarizada de consumidores a los cuales hay que ofrecer productos locales diferenciados y competitivos" (2014: 55), y en la Patagonia ello es posible. De este modo, el destino Patagonia es un lugar donde convergen múltiples movilidades para escenificar una complejidad en la que participan en la mercantilización objetos, elementos, paisajes, animales, personas y comunidades a fin de generar la experiencia única e íntima del color, el sonido, el aroma.
Analíticamente implica una observación compleja, ya que hay una transformación en el uso de los recursos que se refleja en el siguiente testimonio recogido en Futaleufú: "el turista aquí viene por la naturaleza y el río. Antes era un recurso para subsistir y para hacer madera, la leña. Ahora tiene otro plus" (Ganadero de Futaleufú).

Lo señalado, también significa en la población local una modificación de sus expectativas, ya que Futaleufú moderno recién comienza en los años 80, cuando en 1985 se produce el primer descenso en balsa; la comunidad fue descubierta por el mundo por contar con uno de los cinco ríos más importantes para la práctica del rafting y el kayac. Con ello, hoy los adolescentes se entrenan en un ojo de agua en su práctica y los más avezados son contratados por empresas internacionales que los proveen de buenos ingresos al atender la demanda de turistas extranjeros entre diciembre y marzo, y luego, en un circuito norteamericano y europeo. Con ello, la economía de la experiencia también altera la estructura social y laboral de la localidad, ya 
que se requieren: 1) instructores, 2) servicios de logística, 3) alimentación, y 4) dominio de otras lenguas.

Así, en estos lares patagónicos, para algunos la dicha de vivir proviene del encuentro con experiencias nuevas y de ahí que "no haya mayor dicha que vivir con unos horizontes que cambian sin cesar" (Krakahuer, 2013: 86). Por ello, en este modelo de apropiación territorial cargado de seducciones, se trata de oponer la propia vida con un nuevo deseo; de enfrentar las ventajas y desventajas de una vida sedentaria; de cambiar a menudo de lugar, fijar la mirada en distintos detalles, avanzar hacia una vida nómada, hacia experiencias nuevas, no repetitivas, renovar cada día las expectativas.

\section{Conclusiones}

De acuerdo a lo señalado, reconocemos que en la Patagonia ocurren dos fenómenos íntimamente ligados: a) la revalorización de la naturaleza conecta lo local con lo global y viceversa; b) la configuración de un nuevo espacio de identidad, diferenciado de las prácticas tradicionales y en el que confluyen diversos intereses externos al ámbito local. Esta reconfiguración territorial, de coexistencia con elementos antiguos y tradicionales junto a demandas y experiencias modernas, otorga una complejidad a la formación social local, convirtiéndose en un divisor de aguas frente a las elites agrarias tradicionales locales y un nuevo know-how; profundiza los particularismos, avanza hacia la denominación de origen o los productos regionales, demanda la construcción de nuevos equipamientos para el desarrollo de un valor como el ocio (pesca deportiva, trekking, kayak, cabalgatas), genera presiones inmobiliarias y produce impactos gastronómicos alternativos. Asimismo, promueve el desarrollo de un conjunto de actividades no agrarias que implica la llegada y contratación de personal especializado con habilidades bilingües o trilingües, sistemas de transporte y vehículos especiales, vestuarios e indumentarias ad hoc.

El caso descrito, demuestra la definición de una nueva imagen de la naturaleza, configurándose conforme a una clasificación jerárquica de los lugares, donde lo no urbani- zado y mayormente virgen o poco explorado alcanza una nueva posición en la retórica del capitalismo extractivista y en la imagen y fantasía escapista del visitante. Se consume la experiencia única dentro de los límites de lo que no es solo naturaleza, sino un artefacto cultural de gran valor económico.

La retórica de la imagen del otro, y del posible otro en el que puede convertirse, constituye una imagen invertida del nosotros urbano y del limitado alcance de su relación con la naturaleza. El deseo de tránsito de los neocolonos manifiesta la insatisfacción, pero la vida del otro en su adyacencia a la naturaleza se inscribe en una economía del placer y la seducción, representándola como una nueva entidad simbólica.

Los modelos de apropiación y uso minimizan u ocultan lo que ha sido la presencia de la población originaria en relación con sus recursos naturales como parte de su vida y ciclo económico. Asimismo, se oscurece el uso que estos han tenido en los colonos, quienes en más de un siglo han participado de las imágenes fortalecidas y muchos de los relatos paradigmáticos construidos sobre la vida en estas tierras. Con el turismo se impone un saber exógeno-técnico sobre los saberes y prácticas tradicionales de las poblaciones, lo que implica una limitación de uso para los pobladores locales de los recursos disponibles, y una alteración de su ciclo productivo para ajustarse a nuevas demandas y posibilidades. Muy claramente, la vida campesina se constituye en un insumo positivo para el registro del turismo, pero también a este se lo considera por los modelos señalados un depredador al talar el bosque por las mismas empresas y organismos como CONAF, que generan marcos regulatorios locales y a través de modelos de parques de conservación binacionales, a fin de ofrecer continuidad ecosistémica.

A partir de la presentación de los dos modelos de parques de conservación, no es difícil pensar una paradoja: es posible que para salvar los distintos ecosistemas amenazados por las fauces de las fuerzas extractivistas, la naturaleza deba ser vendida, como ocurre con los modelos Patagonia Sur, Parque Pumalín y Estancia Valle Chabuco. En este sentido, los grupos ambientalistas, el Estado 
y algunas formas de la economía capitalista posindustrial se encuentran más cerca que lejos, en cuanto el neoliberalismo cede derechos y otros lo administran a libre arbitrio, es decir, con sus propias reglas. Asimismo, ello conduce como en el modelo Pumalín y Chacabuco a que se instale la figura de un ecologismo como una verdad dura, que induce en su estrategia restaurativa al desplazamiento de las prácticas sociales, culturales y económicas locales constituidas como cultura del trabajo en la ganadería ovejera y vacuna, y en el caso Patagonia Sur, a las ganancias rápidas y de bajo riesgo.

Además, en estos modelos se distinguen dos ejes políticos en el activismo ambiental, ya que en los parques de conservación es siempre "hacia adentro", dado que inicialmente es privado e implica con sus propias reglas. "Hacia afuera", las batallas de los colectivos por la salvaguarda de la naturaleza se dan dentro de los límites del desarrollo sostenible. Detrás de una condición de tierras bajo conservación privada, mezcla de negocios inmobiliarios, desarrollo de infraestructura y reservas naturales, también existe el reconocimiento de que el Estado no tiene todas las capacidades para resguardar las reservas genéticas existentes en estos territorios.

\section{Referencias bibliográficas}

ALISTE, E. y URQUIZA, A. Medio ambiente y sociedad. Conceptos, metodologías y experiencias desde las ciencias sociales y humanas. Santiago de Chile: RIL, 2010.

BECK, U. La sociedad del riesgo: hacia una nueva modernidad. Madrid: Ediciones Paidós Ibérica, 2006.

BOLTANSKY, L. y CHIAPELLO, E.. EI nuevo espíritu del capitalismo. Madrid: Akal, 2002.

BRITTON, S. Tourism, capital and place: toward a critical geography of tourism. Environmental and Planning D: Society and Space, 1991, Vol. 9, № 4, p. 451-478.

BROHMAN, J. New Directions in Tourist for Third World Development. Annals of Tourism Research, 1996, Vol. 23, № 1, p. 48-70.
BUADES, J. Exportando paraísos. La colonización turística del planeta. Barcelona: Alba Sud,. 2014.

CANDIDO, F.; ALMEYDA, J. \& PREMEBIDA, A. O ambiente como questão sociológica: conflitos ambientais em perspectiva. Sociologías, 2014, Año 16, № 35, p. 34-82.

DIMITRIU, A. Producir y consumir lugares: Reflexiones sobre la Patagonia como mercancía. Eptic. Revista de Economía Política de las Tecnologías de la Información y Comunicación, 2002, Vol. IV, № 3, p. 68-99.

EL MERCURIO. El Plan de Land Rover para reforestar la Patagonia y compensar sus emisiones de $\mathrm{CO}_{2} .1^{\circ}$ de abril de 2012. Disponible en Internet: http://www.emol.com/ noticias/economia/2012/03/20/531834/elplan-de-land-rover-parareforestar- la-patagonia-y-compensar-las-emisiones-de-co2.html

FUNDACIÓN TERRAM. Áreas Protegidas Privadas en Chile. Santiago de Chile: TERRAM, 2005.

GALAFASSI, G. Capital, naturaleza y territorio en Patagonia. Rediscutiendo las tesis sobre la acumulación primitiva. A Contracorriente, 2010, Vol 8, № 1 . Disponible en Internet: http://tools.chass.ncsu.edu/open_ journal/index.php/acontracorriente/article/ download/488/752

GARCÍA CANCLINI, N. Las culturas populares en el capitalismo. México, D.F: Nueva Imagen, 1982.

GIUCCI, G. Tierra del Fuego: la creación del fin del mundo. Buenos Aires: Fondo de Cultura Económica, 2014.

GOBIERNO REGIONAL DE AYSÉN / GOBIERNO DE CHILE / GTZ. Atlas Región de Aysén. Santiago de Chile: Lom, 2005.

GONZÁLEZ, R. Los procesos de migración de amenidad y la competitividad de destinos turísticos de montaña del oeste canadiense y de la norpatagonia argentina. Estudios y Perspectivas en Turismo, 2011, Vol. 20, p. 1102-1122. 
HARVEY, D. La condición de la posmodernidad: Investigación sobre los orígenes del cambio cultural. Buenos Aires: Amorrortu editores, 1998.

HIDALGO, R. y ZUNINO, H. Negocio inmobiliario y migración por estilos de vida en la Araucanía lacustre: la transformación del espacio habitado en Villarrica y Pucón. Revista $A \cup S, 2012, N^{\circ} 11$, p.10-13.

HOBSBAWN, E. y RANGER, T. La invención de la tradición. Barcelona: Crítica, 2002.

HOBSBAWN, E. La era del capital, 18481875. Barcelona: Crítica, 1998.

INGLEHART, R. Modernización y posmodernización. El cambio cultural, económico y político en 43 sociedades. Madrid: Siglo XXI, 1998.

JACOBS, J. Muerte y vida en las grandes ciudades. Madrid: Ediciones Península, 1967.

KRAKAUER, J. Hacia rutas salvajes. Santiago de Chile: Zeta, 2013.

LANGMAN, J. Los parques privados en aumento. Patagon Journal, 2014, No 5, p. 1123.

LASCH, S. y URRY, J. Economías de signos y espacio. Sobre el capitalismo de la posorganización. Buenos Aires: Amorrourtu editores, 1998.

LEOPOLD, A. La ética de la tierra. Revista Ambiente y Desarrollo, 2007, Vol. 23, № 1, p. 29-40.

MAGAZINE BUSINESS CHILE. Donde los negocios se juntan con la conservación. 14 de julio de 2010. Disponible en Internet: http:// businesschile.cl/es/noticia/patagonia-sur/donde-los-negocios sejuntan-conla-conservacion

MEDINA, P.J.; RODRÍGUEZ, J. y REYES, S. Capitalismo tardío y territorio. Imaginarios y contradicciones en la Patagonia Chilena. Revista Márgenes, 2013, Vol. 10, № 13, p. 91-102.

MOSS, L. Next steps and the longer view. In: MOSS, L. The amenity migrants. Seeking and sustaining mountains and their cultures. Trowbridge: Cromwell Press, 2006, p. 309319.

MUÑOZ, M.; NÚÑEZ, H. y YAÑEZ, J. Libro Rojo de los sitios para la conservación de la biodiversidad en Chile. Revista Ambiente y Desarrollo, 1997, Vol. XIII, No 3, p. 90-99.

NAESS, A. VVAA Deep Ecology for the 21 st Century. Boston/London: Shambala, 1995.

NOUZEILLES, G. Introducción. En: NOUZEILLES, G. (compiladora). La naturaleza en disputa. Retóricas del cuerpo y del paisaje en América Latina. Buenos Aires: Paidós, 2002, p. 11-38.

NúÑEZ, A.; ALISTE, E. y BELLO, A. El discurso del desarrollo en Patagonia-Aysén: la conservación y la protección de la naturaleza como dispositivos de una renovada colonización. Chile, siglos XX-XXI. Scripta Nova. Revista Electrónica de Geografía y Ciencias Sociales, 2014, Vol. XVIII, No 493 (46). Disponible en Internet: http://www.ub.edu/ geocrit/sn/sn-493/493-46.pdf

OLIVA, J. y CAMARERO, L. Paisajes sociales y metáforas del lugar. Una exploración de la ruralidad itinerante en Navarra. Pamplona: Universidad Pública de Navarra, 2003.

PINE, J. \& GILMORE, J. The Experience Economy. Boston: Harvard Bussines School Press. 1999.

RODRÍGUEZ, J. y REQUENA, M. La reinvención de la autenticidad en el contexto de la mercantilización neoliberal. Sociologías, 2014, Año 16, Nº 35, p. 166-201.

RODRÍGUEZ, J.; MEDINA, P. y REYES, S. Territorio, paisaje y marketing global: Imaginarios en la construcción de la Patagonia como marca. Magallania, 2014, Vol. 42, Nº 2 , p. 109-123.

SILVA, E. Forest, Livelihood, and Grassroot Politics: Chile and Costa Rica Compare. European Review of Latin American and Caribbean Studies, 1999, №66, p. 39-73. 
STONICH, S. Political Ecology of Tourism. Annals of Tourism Research, 1998, Vol. 25, No 1, p. 25-54.

TOMPKINS, D. Prólogo. La tragedia del bosque chileno. En: El futuro y la esperanza. Santiago de Chile: Defensores del bosque chileno, 1998.
ZUNINO, H. e HIDALGO, R. En busca de la utopía verde: migrantes de amenidad en la comuna de Pucón, IX Región de la Araucanía, Chile. Scripta Nova. Revista Electrónica de Geografía y Ciencias Sociales, 2010, Vol. XIV, No 331 (75). Disponible en Internet: http://www.ub.es/geocrit/sn/sn-331/sn-33175.htm 